\title{
Design and properties of new dendritic macromolecules substituted by several triarylamines for organic photovoltaic applications based on Carbazole and Thiophene
}

\section{Wafae Saidi}

Moulay Ismail University: Universite Moulay Ismail

FATIMA AGDA ( $D$ Agdafatima2013@gmail.com )

Universite Sidi Mohamed Ben Abdellah Faculte des Sciences Dhar El Mahraz-Fes

https://orcid.org/0000-0001-7405-9732

\section{TAYEB ABRAM}

Moulay Ismail University: Universite Moulay Ismail

\section{Lahcen Bejjit}

Moulay Ismail University: Universite Moulay Ismail

\section{Mohammed Bouachrine}

École de technologie supérieure: Ecole de technologie superieure

\section{Research Article}

Keywords: Carbazole, DFT, G2TTPG2 3T, Optoelectronic properties, Thiophene.

Posted Date: March 2nd, 2022

DOI: https://doi.org/10.21203/rs.3.rs-1350123/v1

License: (c) (i) This work is licensed under a Creative Commons Attribution 4.0 International License.

Read Full License 


\section{Abstract}

This work proposes a theoretical study of the geometric and optoelectronic properties of some dendritic macromolecules consisting mainly of thiophene and carbazole. First, calculations were performed on a basic molecule called G2TTPG2 3T using the density functional theory (DFT) and varying between 5 different quantum methods to be able to choose the most appropriate which will then be applied to the derivatives of this molecule during the rest of this work, these derivatives were obtained by grafting the following groups: CN, EDOT-S, $\mathrm{OH}, \mathrm{OHOH}, \mathrm{EDOT}, \mathrm{F}$. The objective of this work is to study the effect of this chemical modification, better explore the structure-property relationship and also to search for compounds with the best optoelectronic properties in order to present them for synthesis. The results obtained reveal that the substitution by some groups has reduced the energy of the gap, decreased intercyclic distances and increased the value of the open circuit voltage.

\section{Introduction}

Endowed with excellent electronic and optical properties, organic materials based on $\pi$-conjugated molecules have attracted a lot of attention in several fields of application, they are used in electroluminescent devices [1]-[3], organic transistors OFET[4]-[6], organic solar cells OPVs [7], [8] and in organic batteries [9], [10].

Among the most important factors for determining the physical properties of a $\pi$-conjugated molecule, in particular a polymer is the width of its band gap. Several means have been used to modulate this parameter namely the modification of the chemical structure by the insertion of charge transporters in the skeleton of the conjugated system[11]-[15].

In order to increase the power of conversion and the efficiency of photovoltaic devices, it tends to improve the transfer and charge transport of the exciton and to modify the effect of the electron-donor (D) and acceptor (A) moieties acting as electron donor used in hetero-junction-based organic solar cell. For this reason, we propose, in this chapter, a theoretical study of the geometry and optoelectronic properties of a series of dendritic macromolecules composed mainly of thiophene and carbazole. Several parameters were studied such as the energies of HOMO, LUMO, energy gap, and absorption wavelength $\left(\lambda_{\max }\right) \ldots$ first of all, calculations were made by several quantum methods performed on the base molecule to be able to choose the most appropriate one and which will be applied on the derivatives of the molecule G2TTPG2 $3 T$ [16] during the rest of this work. These derivatives were obtained by grafting the following groups: $\mathrm{CN}$, EDOT-S, $\mathrm{OH}, \mathrm{OHOH}, \mathrm{EDOT}, \mathrm{F}$ and which are named $\mathrm{C} 1, \mathrm{C} 2, \mathrm{C} 3, \mathrm{C} 4, \mathrm{C} 4, \mathrm{C} 5$, and $\mathrm{C} 6$ respectively (Fig. 1). The aim was to study the effect of this chemical modification on the basic structure and to search for compounds with the best optoelectronic properties in order to present them for synthesis.

The results thus obtained will allow, on the one hand, the understanding of the properties of known materials and, on the other hand, the development and the prediction of the properties of those still unknown. 


\section{Theoretical Study Of The Molecule G2ttpg2 3t}

\subsection{The molecule G2TTPG2 $3 T$}

Dendritic macromolecules have unique molecular architectures for a wide variety of applications in different types of devices (optoelectronic and electronic). They can be designed to have conjugated cores for efficient load transport, as well as appropriate terminal groups / chains for good transportability. Unlike conjugated polymers, there are few reports on the applications of these dendrimers based on thiophene in organic solar cells.

Poly-thiophene is a material that is currently attracting great interest, both theoretically and experimentally, it is indeed an excellent model for the study of anunidimensional conductors; easy to dope, it also has a structure that may have topological defects such as polarons and bipolarons. These models are designed to be up to date with the evolution of the properties of potential applications in fields as diverse as electroanalysis, information visualization, energy production and storage. Polythiophene is prepared by electro-polymerization of thiophene; it is obtained in a p-doped and conductive form (doped PT) and can be chemically or electro-chemically reduced (neutral PT).

Being chemically stable, carbazole was incorporated as an important unit in the basic compound for its various advantages, namely its rigidity, which greatly improves the thermal stability of organic compounds.

Finally, the poly-thiophenes and the carbazoles can have a high mobility charge carrier and excellent stability.

In the schema below, we report the synthetic routes of a series of oligothiophenes substituted by several triarylamines, based on a thiophene ring containing $3 \mathrm{X}$-shaped units as shown in Figure 2.

\subsection{Computational methods}

First, and in order to find the most appropriate method that would be used, in the second part of this work, to demonstrate the effect of the different substitutions on the geometric and electronic properties of the compounds derived from the basic molecule, we performed several calculations on the G2TTPG2 3T compound using the density functional theory (DFT) and varying between 5 different exchangecorrelation functions: B3LYP (Becke with three Lee-Yang-Parr parameters)[17], [18], B3PW91[19], BPV86[20], [21], LSDA[22], [23] and MPW1PW91[24]-[26]. The extended atomic orbital base 6-31G (d,p) [27]-[30]was used for all atoms. The calculations were made using the GAUSSIAN 09 program [31].

\subsection{Geometric properties of G2TTPG2 $3 T$}

Table 1 represents the geometric properties obtained by the different theoretical calculation methods for the most stable conformation of G2TTPG2 3T. 
Table 1: Geometric parameters of the most stable conformation obtained by different calculation methods

\begin{tabular}{|llllll|}
\hline Ci-Cj(Å) & $\begin{array}{l}\text { Method1 } \\
\text { (B3LYP) }\end{array}$ & $\begin{array}{c}\text { Method2 } \\
\text { (B3PW91) }\end{array}$ & $\begin{array}{l}\text { Method3 } \\
\text { (BPV86) }\end{array}$ & $\begin{array}{l}\text { Method4 } \\
\text { (LSDA) }\end{array}$ & $\begin{array}{l}\text { Method5 } \\
\text { (MPW1PW91) }\end{array}$ \\
\hline $\begin{array}{l}\text { d1 C20- } \\
\text { N59 }\end{array}$ & 1.396 & 1.392 & 1.396 & 1.375 & 1.390 \\
\hline $\begin{array}{l}\text { d2 C1- } \\
\text { N58 }\end{array}$ & 1.396 & 1.392 & 1.396 & 1.375 & 1.390 \\
\hline $\begin{array}{l}\text { d3 C4- } \\
\text { C8 }\end{array}$ & 1.447 & 1.445 & 1.443 & 1.425 & 1.444 \\
\hline $\begin{array}{l}\text { d4 C13- } \\
\text { C15 }\end{array}$ & 1.447 & 1.445 & 1.443 & 1.425 & 1.444 \\
\hline $\mathbf{q}_{1}$ & 63.8 & 119.9 & 58.0 & 134.2 & 63.3 \\
\hline $\mathbf{q}_{2}$ & 112.4 & 64.3 & 126.9 & 140.4 & 120.9 \\
\hline $\mathbf{q}_{3}$ & 161.7 & 163.6 & 171.9 & 176.5 & 161.7 \\
\hline $\mathbf{q}_{4}$ & 162.9 & 162.5 & 173.5 & 178.2 & 162.8 \\
\hline
\end{tabular}

The examination of the calculated geometrical parameters shows, that the shortening of the distances of intercyclic bonds compared to the normal values of the simple bonds $\mathrm{C}-\mathrm{C}$ or $\mathrm{C}-\mathrm{N}$ highlights the effect of conjugation within these structures.

From the table above, it can be seen that the distances between the carbazole-thiophene unit C20-N59 and C1-N58 are in the order of 1,396 $\AA$ and are similar for both B3LYP and BPV86 methods, while these bonds become shorter for B3PW91, LSDA, MPW1PW91 methods, ranging from $1.375 \AA$ to $1.392 \AA$. Compared to the inter-cyclical distances (C4-C8 and C13-C15), which are in the order of $1.447 \AA$ for the B3LYP method, a decrease is noted for the other methods tested, which vary between $1.425 \AA$ and 1.445 $\AA$.

\subsection{Electronic properties}

The determination of the electronic properties is important for the choice of the functional that will be used in the rest of this study, which is why we proceeded to the theoretical calculation of the HOMO and LUMO values and consequently the energy gap that we will compare with that obtained by experimental measurement [16]. This is part of the process of choosing the most appropriate quantum method for our system. These results are presented in Table 2.

Table 2: HOMO, LUMO and Gap energies obtained by different calculation methods as well as experimental gap of G2TTPG2 $3 T$ 


\begin{tabular}{|llll|}
\hline Method & $\mathrm{E}_{\text {HоMO }}(\mathrm{eV})$ & $\mathrm{E}_{\mathrm{LUMO}}(\mathrm{eV})$ & Egap (eV) \\
\hline BPV86 & -4.256 & -2.685 & $\mathbf{1 . 5 8}$ \\
\hline LSDA & -4.747 & -3.117 & 1.63 \\
\hline MPW1PW91 & -5.049 & -1.904 & 3.14 \\
\hline B3PW91 & -4.901 & -2.084 & 2.81 \\
\hline B3LYP & -4.800 & -1.989 & 2.81 \\
\hline Exp[16] & & & 2.65 \\
\hline
\end{tabular}

The values of the HOMO, LUMO and gap energies of the basic compound G2TTPG2 3T obtained by quantum computation via BPV86, LSDA, MPW1PW91, B3PW91 and B3LYP methods and the gap obtained experimentally are grouped in the table above.

By exploiting these results, we notice that the values found from the B3LYP functional with an extended base 6-31G $(d, p)$ are in good concurrence with the experimental data, also, the B3LYP functional underestimates the $\mathrm{E}_{\mathrm{HOMO}}$ values and overestimates those of $\mathrm{E}_{\mathrm{LUMO}}$, which leads to a wide energy gap.

The value of the energy gap via the B3LYP method $(2.81 \mathrm{eV})$ is the closest to the one that is measured $(2.65 \mathrm{eV})$, so we can deduce that these electronic parameters confirm the choice of this functional which carefully reflects the electronic and geometric properties of the studied compound and which will subsequently be used in the rest of this study so that we can closely examine the effects of the introduction of substituted groups on the geometry and optoelectronic properties of this material.

Figure 4 illustrates the values of the energy gap and also the energies of the frontier orbital's for the different functions tested.

\section{Theoretical Study Of New G2ttpg2 3t Derivatives}

\subsection{Computational methods}

In the following part of this study, we will therefore use the DFT/B3LYP Method which has been able to produce optimal results compared to the other methods; this calculation will be applied to the different derivatives obtained by injecting several groups into the basic molecule G2TTPG2 3T. The base 6-31G (d,

p) was used for all calculations. The absorption energies of the studied compounds are obtained via the ZINDO method, which is highly reliable compared to other methods and has been applied to geometries already optimized, these calculation methods have proven their efficiencies on other conjugated polymers [32]. The calculations were made using the Gaussian 09 program. 
Figure 5 illustrates the optimized structures of the new derivatives obtained from the basic compound G2TTPG2 3T by grafting the following groups CN, EDOT-S, Omet, OmetOmet, EDOT, F. These derivatives are respectively named $\mathrm{C} 1, \mathrm{C} 2, \mathrm{C} 3, \mathrm{C} 4, \mathrm{C} 5$, and $\mathrm{C} 6$ All the geometries of these molecular structures were calculated with the hybrid function B3LYP combined with the base $6-31 \mathrm{G}(\mathrm{d}, \mathrm{p})$ using the GAUSSIAN 09 program [32].

The results obtained show that the optimized structures of the compounds derived from G2TTPG2 3T have a similar conformation (quasi-planar conformation)

The different geometric properties of the molecules corresponding to the structures completely optimized $\mathrm{Ci}(\mathrm{i}=1$ to 6$)$ are presented in Tables 3 and 4.

Table 3: Inter-cyclic distances of the studied molecules Ci (i=1 to 6) obtained by DFT/B3LYP/6-31G (d, p) level

\begin{tabular}{|c|c|c|c|c|c|c|}
\hline Compound & C1 & $\mathrm{C} 2$ & $\mathrm{C} 3$ & C4 & C5 & C6 \\
\hline$d_{1} N_{52}-C_{1}$ & 1.396 & 1.399 & 1.393 & 1.396 & 1.397 & 1.387 \\
\hline$d_{2} C_{4}-C_{6}$ & 1.441 & 1.464 & 1.440 & 1.441 & 1.439 & 1.439 \\
\hline$d_{3} C_{10}-C_{11}$ & 1.442 & 1.464 & 1.441 & 1.442 & 1.439 & 1.439 \\
\hline$d_{4} C_{15}-N_{53}$ & 1.396 & 1.399 & 1.398 & 1.396 & 1.396 & 1.387 \\
\hline
\end{tabular}

Table 4: Dihedral angles of the studied molecules $C i(i=1$ to 6$)$ Obtained by DFT /B3LYP/6-31G (d, $p)$ level

\begin{tabular}{|lllllll|}
\hline $\mathbf{q i}^{(}\left(^{\circ}\right.$ & $\mathrm{C}_{1}$ & $\mathrm{C}_{2}$ & $\mathrm{C}_{3}$ & $\mathrm{C}_{4}$ & $\mathrm{C}_{5}$ & $\mathrm{C}_{6}$ \\
\hline $\mathrm{q}_{1}$ & 96.9 & 109.4 & 124.2 & 96.9 & 94.5 & 125.5 \\
\hline $\mathrm{q}_{2}$ & 162.3 & 76.9 & 179 & 162.3 & 178.4 & 176.7 \\
\hline $\mathrm{q}_{3}$ & 157.6 & 99.4 & 179.2 & 160.1 & 179.5 & 176.7 \\
\hline $\mathbf{q}_{4}$ & 111.2 & 94.7 & 96 & 111.2 & 108.1 & 59.7 \\
\hline
\end{tabular}

The analysis of the results in Table 3 allowed us to observe that the insertion of fluorine ( $F)$ induced a slight decrease in the lengths of the N52-C1, C4-C6, C10-C11, and C15-N53 bonds, these short bonds promote intramolecular charge transfer (ICT).

Whereas for the introduction of the 3,4-ethylenedioxythiophene (EDOT) group, the distances $d_{1}, d_{2}, d_{3}$ and $d_{4}$ increased. The insertion of the cyano group decreases the intercyclic distances N52-C1, C15-N53 and 
increases the other distances C10-C11, C4-C6.

The data in Table 3 show that the distances di ( $i=1$ to 4 ) are shorter for all the compounds, this shows a character $\mathrm{C}=\mathrm{C}$ of the $\mathrm{d}$-bond for all the studied compounds. It can be deduced that the contact between the two carbazole-thiophene fragments is crucial, which improves the ICT character for these six compounds; this is important to shift the absorption spectra towards red.

\subsection{Electronic properties}

Among the parameters that most influence the electronic properties of conjugated organic materials there is the energy of the gap, which is in turn directly related to the energies of the HOMO and LUMO orbital levels, hence the calculation of these orbital frontiers (theoretical or experimental) is essential. Figure 5 schematizes the electron density distributions of the G2TTPG2 3T molecule and its derivatives.

For the HOMO level, it is noted that for the basic compound as well as all the other studied compounds $\mathrm{Ci}$ ( $i=1$ to 6 ) the electron density is incorporated into the central group.

As regards the electron density of the LUMO orbital, it is localized on one of the two carbazole units for compounds $\mathrm{C}_{1}, \mathrm{C}_{2}, \mathrm{C}_{3}, \mathrm{C}_{4}, \mathrm{C}_{5}$ and the basic compound G2TTPG2 3T, while for the compound $\mathrm{C}_{6}$ the electron density of its LUMO orbital is visible on both units of carbazole, this location of the electron density on carbazole indicates that it's the richest part in electron $\pi$.

This shows that the transfer from an electron donating party, which is localized in the center of the compound (unit of carbazole), to an acceptor, it's for the $\mathrm{C}_{1}, \mathrm{C}_{2}, \mathrm{C}_{3}$ and $\mathrm{C}_{4}$ molecules.

The gap energy is among the most important parameters to determine the quality of $\pi$-conjugated compounds. To obtain optimal results, the most cost-effective technique is to increase the aromaticity of these compounds by introducing or attaching the nucleus by $\pi$-conjugated electron donor groups.

Then to better understand the effect of the incorporation of different fragments on optoelectronic properties, we have, in the next part, examined with precision the HOMO and LUMO energy levels for the G2TTPG2 3T compound and its derivatives. The theoretical calculation of the HOMO and LUMO values by the DFT/B3LYP/6-31G $(d, p)$ method allowed us to analyze these levels and also to calculate the gap energy which is defined as the difference between $\mathrm{E}_{\mathrm{HOMO}}$ and $\mathrm{E}_{\mathrm{LUMO}}$.

Table 5: The HOMO, LUMO and Gap energies of the studied molecules obtained by DFT /B3LYP/6-31G (d, p) level 


\begin{tabular}{|lrll|}
\hline Compound & $\mathrm{E}_{\text {HOMO }}$ & $\mathrm{E}_{\text {LUMO }}$ & Egap (eV) \\
\hline G2TTPG2 3T & -4.800 & -1.989 & 2.81 \\
\hline C1 & -4.880 & -3.729 & $\mathbf{1 . 1 5}$ \\
\hline C2 & -4.768 & -1.279 & 3.49 \\
\hline C3 & -4.636 & -1.862 & 2.78 \\
\hline C4 & -4.637 & -1.722 & 2.91 \\
\hline C5 & -4.690 & -1.570 & 3.12 \\
\hline C6 & -4.854 & -2.323 & 2.53 \\
\hline
\end{tabular}

Table 5 presents the values of the HOMO, LUMO and Egap energies of the studied molecules. The energies of HOMOs range from $-4,880 \mathrm{eV}$ to $-4,636 \mathrm{eV}$ while the energies of LUMOs range from $\mathrm{eV}$ to $-1.279 \mathrm{eV}$.

Concerning the gap energies, the values are classified as follows: C1 $(1.151 \mathrm{eV})<\mathrm{C} 6(2.531 \mathrm{eV})<\mathrm{C} 3$ $(2.774 \mathrm{eV})<\mathrm{C} 4(2.915 \mathrm{eV})<\mathrm{C} 5(3.120 \mathrm{eV})<\mathrm{C} 2(3.489 \mathrm{eV})$

We notice that the energy gap increases as we move from the compound $C_{1}$ to the compound $C_{2}$, this is due to the increase in the order of the $\pi$ conjugation and the substituent that acts as a donor electron in the molecule.

By analyzing these results, it is noted that substitution by the 3,4-ethylenedioxythiophene fragment increases the energy of the LUMO and consequently increases the gap (for the compounds $\mathrm{C}_{2}$ and $\mathrm{C}_{5}$ ), whereas the introduction of the cyano group in the compound $\mathrm{C} 1$ decreased the energy of LUMO which resulted in a decrease in the gap energy.

It can be deduced from these interpretations that the best gap energy values obtained are for the two compounds $\mathrm{C}_{1}(1.151 \mathrm{eV})$ and $\mathrm{C}_{6}(2.531 \mathrm{eV})$ which have been substituted by the cyano group and Fluorine.

\section{Absorption Properties}

Our study is ongoing and we are now focusing on the absorption properties of these new G2TTPG2 3T based compounds to see the effect of the insertion of the various groups mentioned above and to understand the probable electronic transitions of the 6 compounds. This study is also very important since the energy of the gap, which is a very decisive factor in predicting the optoelectronic characteristics of a material, is closely related to the absorption wavelength.

And for this purpose, we have determined, from the geometric optimized structures by the B3LYP quantum chemistry method with the 6-31 G $(d, p)$ base, the UV-visible spectra and calculated the values of 
the maximum wavelengths, the oscillation force and the excitation energies

Table 6 groups the above-mentioned parameters obtained using the ZINDO method.

Table 6: Absorption properties for the different studied compounds obtained by the ZINDO/DFT: B3LYP/6$31 G(d, p)$ method

\begin{tabular}{|lllll|}
\hline Compound & $\lambda_{\max }(\mathrm{nm})$ & Energy $(\mathrm{eV})$ & $\mathrm{f}$ & Electronic Transitions (\%) \\
\hline G2TTPG2 3T & 462.57 & 2,68 & 1.55 & HOMO->LUMO (80\%) \\
\hline $\mathrm{C}_{1}$ & 487.66 & 2.54 & 1.12 & H-8->LUMO (71\%) \\
\hline $\mathrm{C}_{2}$ & $\mathbf{3 4 8 . 1 3}$ & 3.56 & 1.61 & H-4->LUMO (47\%) \\
\hline $\mathrm{C}_{3}$ & 492.91 & 2.51 & 1.40 & HOMO->LUMO (86\%) \\
\hline $\mathrm{C}_{4}$ & 477.94 & 2.59 & 1.27 & HOMO->LUMO (78\%) \\
\hline $\mathrm{C}_{5}$ & 496.96 & 2.49 & 1.31 & HOMO->LUMO (90\%) \\
\hline $\mathrm{C}_{6}$ & 494.64 & 2.50 & 1.50 & H-4->LUMO (63\%) \\
\hline
\end{tabular}

Table 6 shows the values of the maximum absorption wavelengths ( $\lambda$ max). The transition character and the oscillation force of the absorption bands in the UV-visible region for all calculated compounds.

The maximum absorption wavelengths of the different studied compounds increase in the following order: $\mathrm{C}_{2}(348.13 \mathrm{~nm})<$ G2TTPG2-3T $(462.57 \mathrm{~nm})<\mathrm{C}_{4}(477.94 \mathrm{~nm})<\mathrm{C}_{1}(487.66 \mathrm{~nm})<\mathrm{C}_{3}(492.91 \mathrm{~nm})<$ $\mathrm{C}_{6}(494.64 \mathrm{~nm})<\mathrm{C}_{5}(496.96 \mathrm{~nm})$

It can be seen that the insertion of the 3.4-ethylenedioxythiophene fragment has increased the maximum absorption wavelength and therefore shows a bathochromic shift from C2 to C5.

Then these wavelengths. Which result from the electronic transition of S0 $\rightarrow \mathrm{S} 1$ (HOMO $\rightarrow$ LUMO). increase gradually with the increase in conjugation lengths which is in turn due to the introduction of different groups in the studied compounds.

We can then deduce that it is the C5 compound that has the longest wavelength. Which is $496.96 \mathrm{~nm}$.

The obtained values from the maximum absorption $\lambda_{\max }$ therefore ranging from $348.13 \mathrm{~nm}$ to $496.96 \mathrm{~nm}$ are characteristic of the $\pi$-conjugated materials and thus make it possible to consider their use in many applications in the field of optoelectronics.

\section{Photovoltaic Properties}


For each device. The open circuit voltage Voc is the maximum voltage that the device can produce in an open circuit of the heterojunction type. To show whether an effective charge transfer will occur between donor and acceptor. it is essential to know the HOMO and LUMO energy levels for both donors and acceptors [33].

The compounds studied $\mathrm{C}_{1} \cdot \mathrm{C}_{2} \cdot \mathrm{C}_{3} \cdot \mathrm{C}_{4} \cdot \mathrm{C}_{5}$ and $\mathrm{C}_{6}$ have a high capacity. In excited states. to inject electrons into the ITO electrodes [32].

The acceptors used are fullerene derivatives at $56 \pi$-electrons and which have been synthesized by Y-Abe et al [34]. These acceptors have already been used in previous works.

On the other hand. To better evaluate the performance of a photovoltaic cell. The power conversion efficiency (PCE) can be calculated according to the following equation:

$$
\mathrm{CE}=\frac{\mathrm{FF} \times \mathrm{Voc} \times \mathrm{Jsc}}{\operatorname{Pin}}
$$

Hence: Pin: density of incident power.

Jsc: short-circuit current.

Voc: open circuit voltage.

FF: form factor.

From the previous equation. We note that the open circuit voltage closely influences the conversion efficiency.

In this study. the value of the open circuit voltage will be theoretically estimated by a simple relationship that links the HOMO energy of the donor material (Ci) and the LUMO energy of the acceptor material [35]. [36]:

Voc $=\mid E_{\text {HоMо }}$ (Donor) $|-| E_{\text {LUMO }}$ (Acceptor) $\mid-0.3$

We also note a which is determined by the difference in LUMO energy of the studied compounds and that of the acceptors [37]:

$a=E_{\text {LUMO }}$ (Donor) $-E_{\text {LUMO }}$ (Acceptor)

Table 7: Energy values for HOMO. LUMO. Voc and a of the studied compounds with PCBM. C60 and SIMEFC acceptors 


\begin{tabular}{|llllllllll|}
\hline & & & \multicolumn{3}{c}{ PCBM } & & C60 & \multicolumn{3}{c|}{ SIMEFC } \\
\hline Compound & E $_{\text {HOMO }}$ & $\mathrm{E}_{\text {LUMO }}$ & $\mathrm{V}_{\text {OC }}$ & $\mathbf{a}$ & $\mathrm{V}_{\text {OC }}$ & $\mathbf{a}$ & $\mathrm{V}_{\text {OC }}$ & $\mathbf{a}$ \\
\hline G2TTPG2 3T & -4.80 & -1.98 & 0.70 & 1.81 & 0.71 & 1.80 & 0.76 & 1.75 \\
\hline C1 & -4.88 & -3.72 & 0.78 & 0.08 & 0.80 & 0.06 & 0.84 & 0.02 \\
C2 & -4.76 & -1.27 & 0.66 & 2.52 & 0.67 & 2.51 & 0.72 & 2.46 \\
C3 & -4.63 & -1.86 & 0.53 & 1.93 & 0.54 & 1.92 & 0.59 & 1.87 \\
C4 & -4.63 & -1.72 & 0.53 & 2.07 & 0.54 & 2.06 & 0.59 & 2.01 \\
C6 & -4.69 & -1.57 & 0.59 & 2.23 & 0.60 & 2.21 & 0.65 & 2.17 \\
\hline PCBM & -4.85 & -2.32 & 0.75 & 1.47 & 0.76 & 1.46 & 0.81 & 1.41 \\
\hline C60 & - & -3.80 & & & & & & \\
\hline SIMEFC & - & -3.78 & & & & & & \\
\hline
\end{tabular}

As it can be seen in Tables 7 and 8. The theoretical values obtained from the open circuit voltage (Voc) for all the studied compounds range from $0.53 \mathrm{eV}$ to $0.84 \mathrm{eV}$. These values are approximately similar to those obtained with macromolecules having proved their effectiveness. So they are moderately sufficient to have an effective electron injection. Then we can deduce that all the studied molecules can be used as electron donors in solar cells.

From the results in the tables. It is noted that compound $\mathrm{C}_{1}$ has the highest open circuit voltage value $(0.84 \mathrm{eV})$. Which confirms the results obtained previously in determining the electronic properties of the studied compounds.

It is then understood that the decrease in the HOMO of the $\pi$-conjugated molecule and the increase in the LUMO of the acceptor causes an increase in the Voc value which leads to a high efficiency of the solar cells.

From this analysis. It can be infer that these molecules can be used as electron donor materials in the $\mathrm{BHJ}$ cell. Because the electron injection process will take place from the molecule to the acceptor's conduction band.

Table 8: Energy values for HOMO. LUMO. Voc and a of the studied compounds with C60(Ind). C60(Qm) and PCBMe acceptors 


\begin{tabular}{|llllllllll|}
\hline & & \multicolumn{3}{c}{ C60(Ind) } & \multicolumn{2}{c|}{ C60(Qm) } & \multicolumn{3}{c|}{ PCBMe } \\
\hline Compound & E $_{\text {HOMO }}$ & $\mathrm{E}_{\text {LUMO }}$ & $\mathrm{V}_{\text {OC }}$ & $\mathrm{a}$ & $\mathrm{V}_{\text {OC }}$ & $\mathrm{a}$ & $\mathrm{V}_{\text {OC }}$ & $\mathrm{a}$ \\
\hline G2TTPG2 3T & -4.80 & -1.98 & 0.74 & 1.77 & 0.72 & 1.79 & 0.70 & 1.81 \\
\hline C1 & -4.88 & -3.72 & 0.82 & 0.04 & 0.80 & 0.06 & 0.78 & 0.08 \\
\hline C2 & -4.76 & -1.27 & 0.70 & 2.48 & 0.68 & 2.50 & 0.66 & 2.52 \\
\hline C3 & -4.63 & -1.86 & 0.57 & 1.89 & 0.55 & 1.91 & 0.53 & 1.93 \\
\hline C4 & -4.63 & -1.72 & 0.57 & 2.03 & 0.55 & 2.05 & 0.53 & 2.07 \\
\hline C5 & -4.69 & -1.57 & 0.63 & 2.19 & 0.61 & 2.21 & 0.59 & 2.23 \\
\hline C6 & -4.85 & -2.32 & 0.79 & 1.43 & 0.77 & 1.45 & 0.75 & 1.47 \\
\hline C60(Ind) & - & -3.76 & & & & & & \\
\hline C60(Qm) & - & -3.78 & & & & & & \\
\hline PCBMe & - & -3.80 & & & & & & \\
\hline
\end{tabular}

\section{Conclusion}

In this work. We managed to carry out a detailed theoretical study on a new macromolecules obtained by insertion of different groups to a basic compound named G2TTPG2 3T. The aim was to observe the effect of the chemical modification on these materials. Thus it was possible to analyze the geometries and electronic properties of these compounds using the DFT(B3LYP) method with the 6-31G (d. p) base.

The effect of the introduced groups on the structural and optoelectronic properties of these materials and the possibility of proposing them for synthesis for use in photovoltaics were discussed.

The main results are as follows:

- The introduction of the 3.4-ethylenedioxythiophene (EDOT) group increased the distances $d_{1} \cdot d_{2} \cdot d_{3}$ and $d_{4}$. While the insertion of the cyano group decreased the intercyclic lengths N52-C1. C15-N53.

- The best gap energy values obtained are for the two compounds C1 (1.151 eV) and C6 (2.531 eV) which have been substituted by the cyano group and Fluorine.

- Whereas for the compounds C2 and C5. The gap values are greater than 3. So these compounds can be used in other applications other than solar cells.

- The compound $\mathrm{C}_{5}$ has the longest wavelength which is $496.96 \mathrm{~nm}$.

- The theoretical values obtained from (Voc) for all the studied compounds vary from $0.536 \mathrm{eV}$ to 0.84 $\mathrm{eV}$. These values are moderately sufficient to have an effective injection of electrons. We note that the best Voc are obtained for the studied compounds in couple with the SMIFE acceptor. 
- The compound $\mathrm{C} 1$ has the highest open circuit voltage value $(0.84 \mathrm{eV})$.

In summary. We note that the substitution by the cyano group has:

* Reduced the gap energy.

* Decreased inter-cyclic distances.

* Increased the value of the open circuit voltage.

This chronology of theoretical calculations helps us to predict the optoelectronic properties of materials before they are synthesized and to propose new architectures for use in photovoltaics.

\section{Declarations}

\section{Declaration of competing}

The authors declare that they have no known competing financial interests or personal relationships that could have appeared to influence the work reported in this paper.

\section{Funding}

Not applicable

\section{Data Availability}

All data generated or analyzed and related materials (with supplementary materials) are included in this manuscript.

\section{Code availability}

The calculations have been carried out using Gaussian 09 and GaussView version 6.0 provided by Gaussian, Inc.

\section{Conflict of interest}

The authors declare no competing interests

\section{Contributions}

Mohammed. BOUACHRINE conceived of the presented idea.

Wafae.SAIDI developed the theory and performed the computations and writhed the article Fatima . AGDA and Tayeb. ABRAM verified the analytical methods. 
Lahcen BEJJIT encouraged wafae SAIDI to investigate and supervised the findings of this work. All authors discussed the results and contributed to the final manuscript.

\section{References}

1. P. L. T. Boudreault. N. Blouin and M. Leclerc (2008) Poly(2.7-carbazole)s and related polymers.Adv. Polym. Sci. 212(1): 99-124.https://doi.org/10.1007/12_2008_139

2. M. J. Thompson (1984) Thin Film Transistors for Large Area Electronics.J. Vac. Sci. Technol. B Microelectron. Nanom. Struct. 2(4):827-834.https://doi.org/10.1116/1.582902

3. R. E. Gill. G. G. Malliaras. J. Wildeman. and G. Hadziioannou (1994) Tuning of photo- and electroluminescence in alkylated polythiophenes with well-defined regioregularity. $A d v$. Mater.6(2):132-135.https://doi.org/10.1002/adma.19940060206.

4. A. Dodabalapur. L. Torsi and H. E. Katz (1995) Organic transistors: Two-dimensional transport and improved electrical characteristics.Science. 268(5208):270-271.DOI: 10.1126/science.268.5208.270

5. A. Kraft. A. C. Grimsdale. and A. B. Holmes (1998) Electroluminescent Conjugated Polymers - Seeing Polymers in a New Light.Angew. Chemie - Int. Ed. 37(4):402-428.https://doi.org/10.1002/(SICI)15213773.

6. D. H. Kim. J. Ohshita. K. H. Lee. Y. Kunugi and A. Kunai (2006) Synthesis of $\pi$-conjugated oligomers containing dithienosilole units. Organometallics. 25(6):15111516.https://doi.org/10.1021/om0510122.

7. A. G. Manoj and K. S. Narayan (2003) Photovoltaic properties of polymer p-n junctions made with P30T/BBL bilayers.Opt. Mater. (Amst). 21:417-420.https://doi.org/10.1016/S0925-3467(02)001726.

8. M. M.Wienk. J. M. Kroon. W. J. H. Verhees. J. Knol. J. C. Hummelen. P. A. van Hal and R. A. J. Janssen (2003) Efficient methano[70]fullerene/MDMO-PPV bulk heterojunction photovoltaic cells.Angew. Chemie - Int. Ed. 42(29):3371-3375.https://doi.org/10.1002/anie.200351647.

9. Q. Deng. J. Xue. W. Zou. L. Wang. A. Zhou. and J. Li (2016) The electrochemical behaviors of $\mathrm{Li} 2 \mathrm{C} 8 \mathrm{H} 4 \mathrm{O} 6$ and its corresponding organic acid $\mathrm{C} 8 \mathrm{H} 6 \mathrm{O} 6$ as anodes for Li-ion batteries.J. Electroanal. Chem. 761:74-79.https://doi.org/10.1016/j.jelechem.2015.12.005.

10. X. Li. Q. Sun. J. Liu. B. Xiao. R. Li. and X. Sun (2016) Tunable porous structure of metal organic framework derived carbon and the application in lithium-sulfur batteries.J. Power Sources. 302:174179.https://doi.org/10.1016/j.jpowsour.2015.10.049.

11. Z. El Malki.K. Hasnaoui. S. M. Bouzzine. L. Bejjit. M. Haddad. M. Hamidi and M. Bouachrine(2010) Chemical Synthesis. Electronic Study. and Vibrational Analysis of a New Organic Copolymer Based on PVK and 3-nhexylthiophene.SRX Chem. 2010:1-8.https://doi.org/10.3814/2010/346843.

12. C. Ego.D. Marsitzky. S. Becker. J. Zhang.A. C. Grimsdale. K. Mullen. J. D. MacKenzie. C. Silva and R. H. Friend (2003) Attaching perylene dyes to polyfluorene: Three simple. efficient methods for facile 
color tuning of light-emitting polymers. J. Am. Chem. Soc. 125(2):437443.https://doi.org/10.1021/ja0205784.

13. Dieter Neher (2001) Polyfluorene homopolymers: Conjugated liquid-crystalline polymers for bright blue emission and polarized electroluminescence.Macromol. Rapid Commun. 22(17):13651385.https://doi.org/10.1002/1521-3927(20011101)22.

14. E. Sezer. M. Van Hooren. A. S. Saraç and M. L. Hallensleben (1999) Synthesis and Electrochemical Polymerization of Ter-arenes Based on N-Ethyl Carbazole and Thiophene.J. Polym. Sci. Part A Polym. Chem. 37(4):379-381.https://doi.org/10.1002/(SICI)1099-0518.

15. K. Hasnaoui. A. Makayssi. M. Hamidi and M. Bouachrine (2008) Computational study on geometric and electronic properties of 3 . 6-carbazole based conjugated polymers. J. Iran. Chem. Res. 1(1): 6777.

16. J. Lu. P. F. Xia. P. K. Lo. Y. Tao and M. S. Wong (2006) Synthesis and properties of multi-triarylammesubstituted carbazole-based dendrimers with an oligothiophene core for potential applications in organic solar cells and light-emitting diodes. Chem. Mater. 18(26):61946203.https://doi.org/10.1021/cm0621110.

17. C. Lee. W. Yang. and R. G. Parr (1988) Development of the Colle-Salvetti correlation-energy formula into a functional of the electron density.Phys. Rev. B. 37(2):785789.https://doi.org/10.1103/PhysRevB.37.785.

18. Axel D. Becke (1993) Density-functional thermochemistry. III. The role of exact exchange.J. Chem. Phys. 98(7):5648-5652.https://doi.org/10.1063/1.464913.

19. J. F. Dobson. G. Vignale and M. P. Das (1998) Recent Progress and New Directions. in Electronic Density Functional Theory. 1st ed. X. 396.

20. John P. Perdew(1986) Density-functional approximation for the correlation energy of the inhomogeneous electron gas. Phys. Rev. B. 33(12):882224.https://doi.org/10.1103/PhysRevB.33.8822.

21. A. D. Becke (1988) Density-fnnctional exchange-energy approximation with correct asymptotic behavior.Phys. Rev. A. 38(6):3098-3100.https://doi.org/10.1103/PhysRevA.38.3098.

22. L. Hedin and B. I. Lundqvist (1971) Explicit local exchange-correlation potentials.J. Phys. C Solid St. Phys. 4(14):2064-2083.https://doi.org/10.1088/0022-3719/4/14/022.

23. H. Paulsen and A. X. Trautwein (2006) Density Functional Theory Calculations for Spin Crossover Complexes.Spin Crossover Transit. Met. Compd. III. 235:197-219.https://doi.org/10.1007/b95428.

24. C. Adamo and V. Barone (1998) Exchange functionals with improved long-range behavior and adiabatic connection methods without adjustable parameters: The mPW and mPW1PW models.J. Chem. Phys. 108(2):664-675.https://doi.org/10.1063/1.475428.

25. John P. Perdew. J. A. Chevary. S. H. Vosko. Koblar A. Jackson. Mark R. Pederson. D. J. Singh and Carlos Fiolhais (1993) Erratum: Atoms. molecules. solids. and surfaces: Applications of the generalized gradient approximation for exchange and correlation.Phys. Rev. B. 46(11):66716687.https://doi.org/10.1103/PhysRevB.46.6671. 
26. H. Arslan and Ö. Algül (2008) Vibrational spectrum and assignments of 2-(4-methoxyphenyl)-1Hbenzo[d]imidazole by ab initio Hartree-Fock and density functional methods. Spectrochim. Acta - Part A Mol. Biomol. Spectrosc. 70(1):109-116.https://doi.org/10.1016/j.saa.2007.07.027.

27. R. Ditchfield. W. J. Hehre. and J. A. Pople (1971) Self-consistent molecular-orbital methods. IX. An extended gaussian-type basis for molecular-orbital studies of organic molecules.J. Chem. Phys. 54(2):720-724.https://doi.org/10.1063/1.1674902.

28. Si M. Bouzzine. M. Hamidi and M. Bouachrine (2009)DFT study of bridged oligo(bithiophene)s.Conformational analysis and opto-electronic properties. Orbital: Elec. J. Chem. 1(2):203-214.

29. P. C. Hariharan and J. A. Pople (2006) Accuracy of $A H_{n}$ equilibrium geometries by single determinant molecular orbital theory.Mol. Phys. 27(1):209-214.https://doi.org/10.1080/00268977400100171.

30. M. S. Gordon (1980) The isomers of silacyclopropane.Chem. Phys. Lett. 76(1):163168.https://doi.org/10.1016/0009-2614(80)80628-2.

31. M. J. Frisch. G. W.Trucks. H. B.Schlegel. G. E.Scuseria. M. A.Robb (2009) Gaussian 09. Revision A02.

32. S. V. Meille. A. Farina. F. Bezziccheri. and M. C. Gallazzi(1994) The influence of alkoxy side chains on the conformational flexibility of oligo- and polythiophenes.Adv. Mater. 6(11): 848851.https://doi.org/10.1002/adma.19940061109.

33. H. Derouiche and V. Djara (2007) Impact of the energy difference in LUMO and HOMO of the bulk heterojunctions components on the efficiency of organic solar cells.Sol. Energy Mater. Sol. Cells. 91(13):1163-1167.https://doi.org/10.1016/j.solmat.2007.03.015.

34. Y. Ma. K. Uchiyama. H. Ueno. H. Okada. H. Moriyama. and Y. Matsuo (2019) Highly soluble: C 2vsymmetrical fullerene derivatives: Efficient synthesis. characterization. and electrochemical study. Org. Chem. Front. 6(9):1372-1377.https://doi.org/10.1039/C9Q000056A.

35. M. C. Scharber. D. Mühlbacher. M. Koppe. P. Denk. C. Waldauf. A. J. Heeger and C. J. Brabec (2006) Design Rules for Donors in Bulk-Heterojunction Solar Cells-Towards 10 \% Energy-Conversion Efficiency.Adv. Mater. 18(6):789-794.https://doi.org/10.1002/adma.200501717.

36. C. J. Brabec. A. Cravino. D. Meissner. N. S. Sariciftci. T. Fromherz. M. T. Rispens. L. Sanchez. and J. C. Hummelen (2001) Origin of the Open Circuit Voltage of Plastic Solar Cells.Advenced Funct. Mater. 11(5):374-380.https://doi.org/10.1002/1616-3028.

37. Y. He. H. Y.Chen. J. Hou. and Y. Li (2010) Indene-C 60 Bisadduct: A New Acceptor for HighPerformance Polymer Solar Cells.J. Am. Chem. Soc. 132(19):13771382.https://doi.org/10.1021/ja908602j.

\section{Figures}




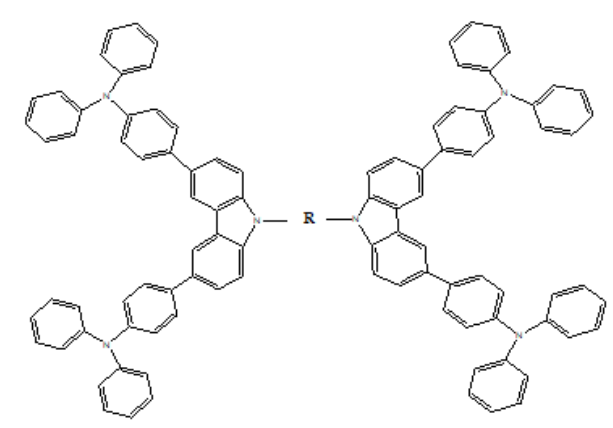

$R=G 2 T T P G 23 T: 1,2,3,4,5,6$
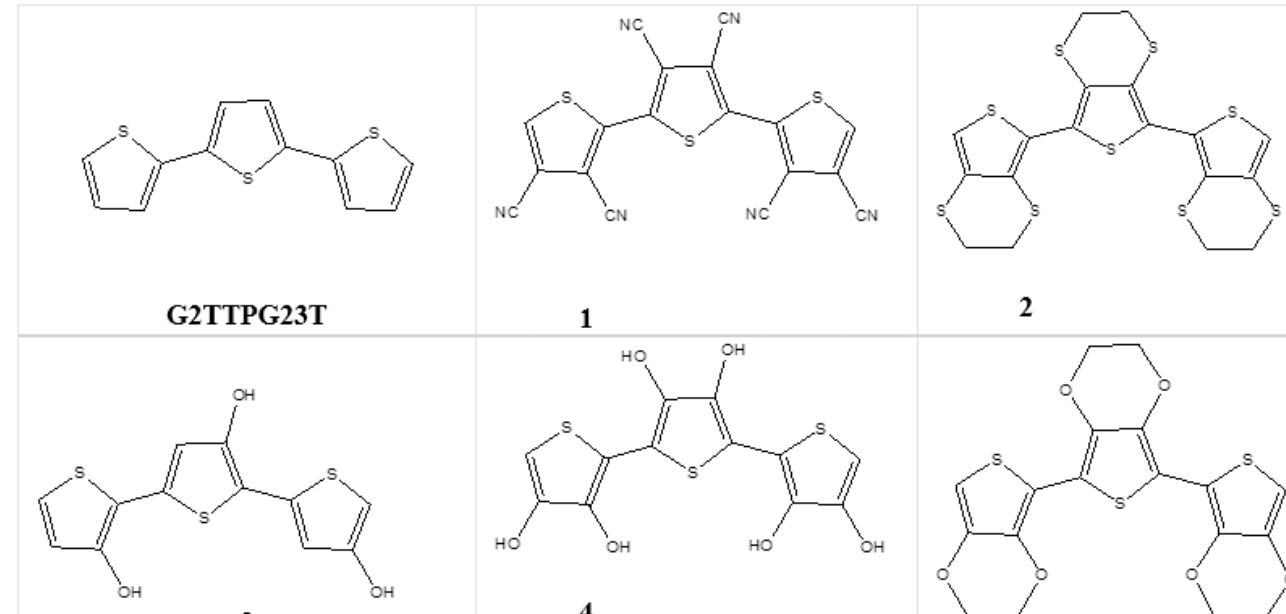

3

1

2

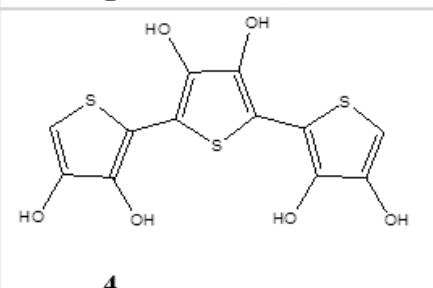

4
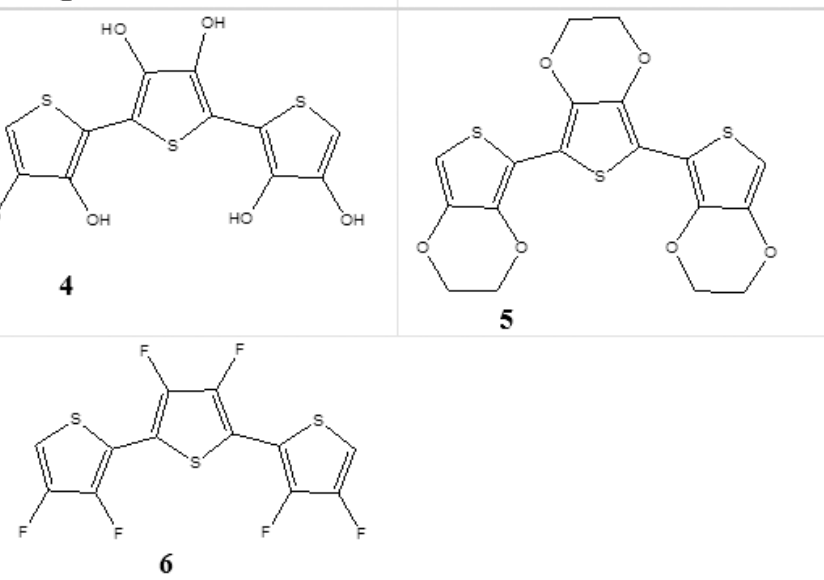

Figure 1

Chemical structure of the basic structure G2TTPG2 3T and its derivatives Ci ( $i=1$ to 6 ) 
<smiles>c1ccc(Nc2ccccc2)cc1</smiles>

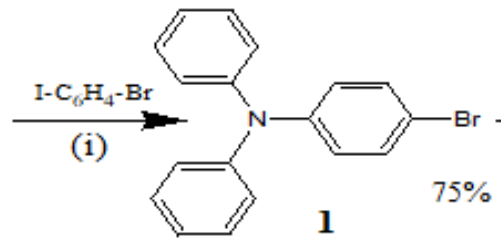

(ii)
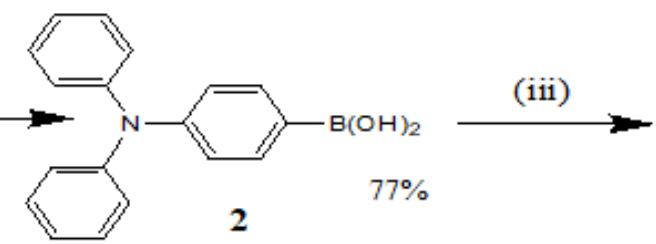<smiles>O=S(=O)(O)c1ccc2[nH]c3ccc(-c4ccc(N(c5ccccc5)c5ccccc5)cc4)cc3c2c1</smiles>

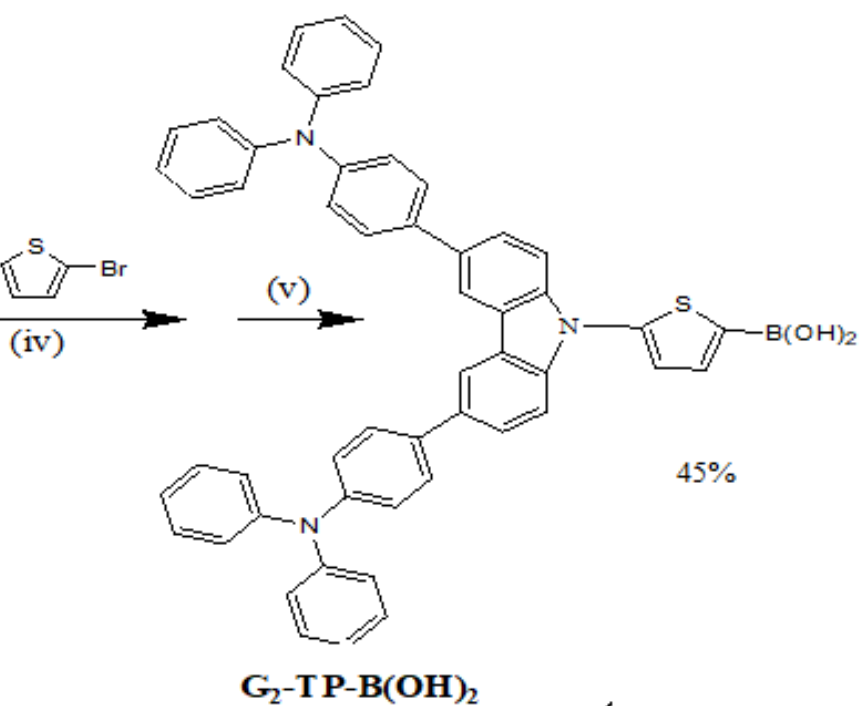

$\mathrm{G}_{2}-\mathbf{H}$

$\mathrm{G}_{2}-\mathrm{T}$ P-B (OH)

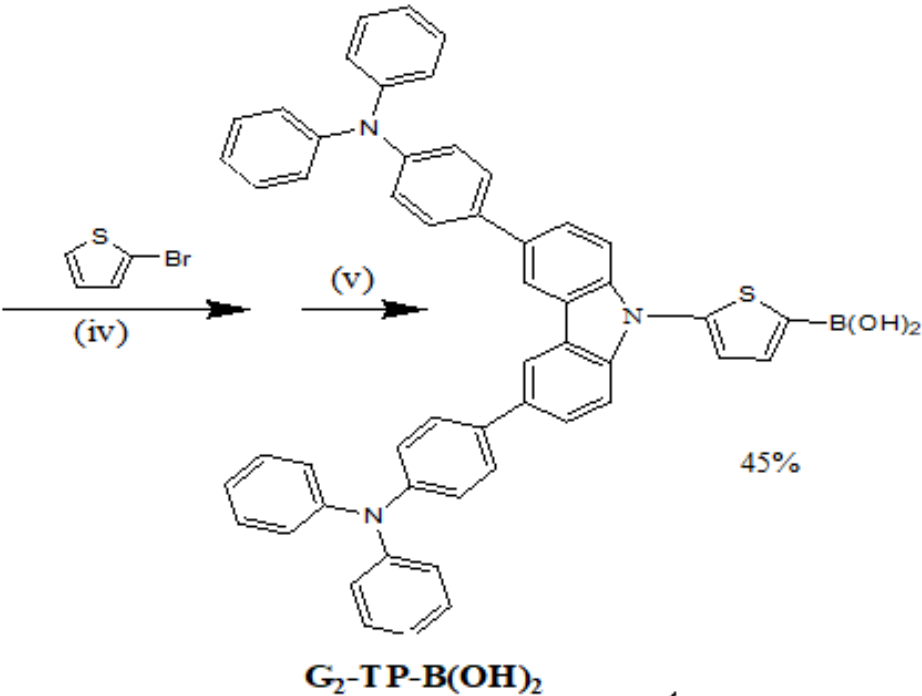

(iv)
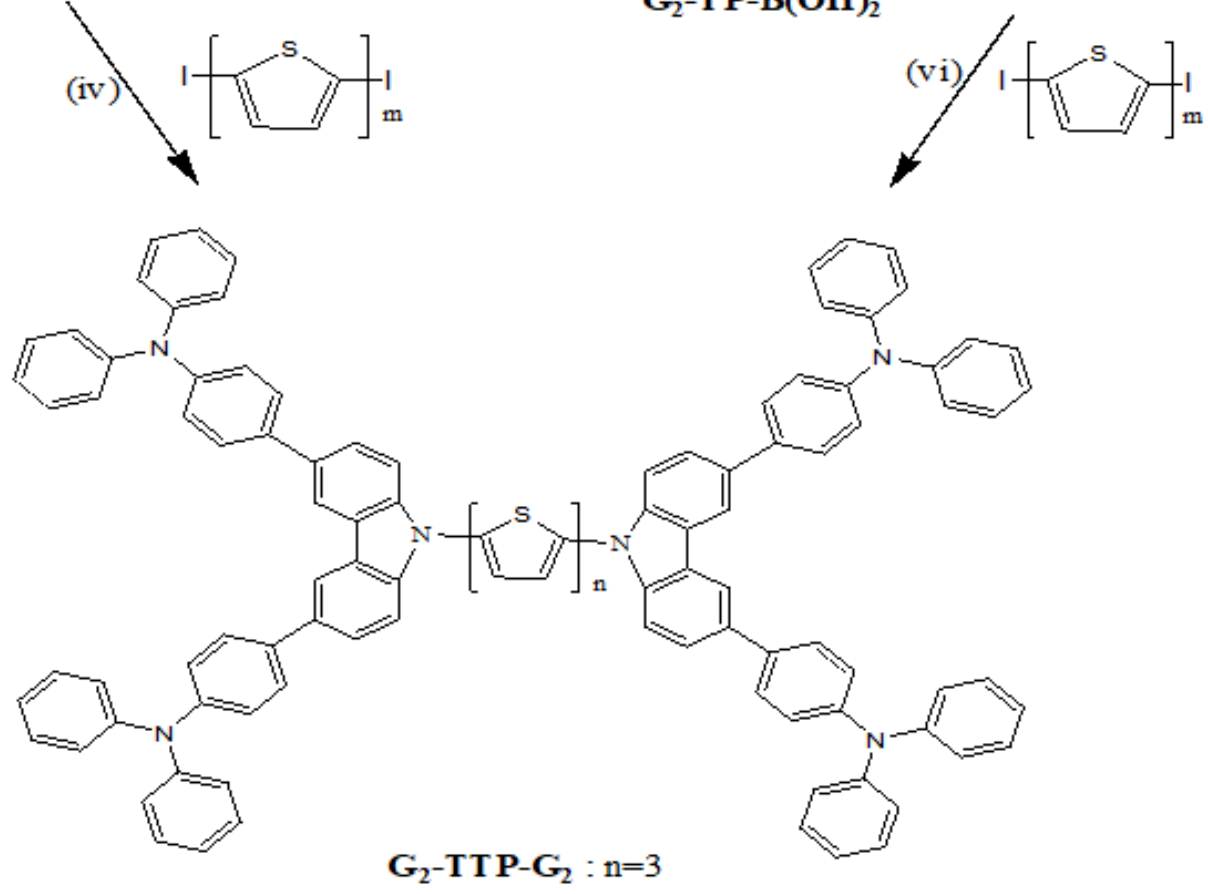

Figure 2

Synthesis of the molecule G2TTPG2 3T[16].

(i) 1 mole\% Cult, 10 mole\% 1,2-trans-cyclohexadiamine, NaOtBu, dioxane, $110{ }^{\circ} \mathrm{C}$

(ii) a 1.5 equiv. $n$-BuL, $T H F,-78{ }^{\circ} \mathrm{C} ; b \mathrm{~B}\left(\mathrm{OCH}_{3}\right)_{3} ; \mathrm{C} 6 \mathrm{M} \mathrm{HCl}$

Page $18 / 24$ 
(iii) 3,6-dibromocarbazole, 2.5 mole\% $\mathrm{Pd}\left(\mathrm{PPh}_{3}\right)_{4}, \mathrm{THF}, 2 \mathrm{M} \mathrm{K}_{2} \mathrm{CO}_{3}, 80^{\circ} \mathrm{C}$

(iv) 25 mole\% Cul, 250 mole\% 1,2-trans-cyclohexadiamine, NaOtBu, dioxane, $110{ }^{\circ} \mathrm{C}$

(v) a 4 equiv. $n-B u L i, T H F, b B\left(\mathrm{OCH}_{3}\right)_{3} ; C 2 \mathrm{M} \mathrm{HCl}$

(vi) $5 \mathrm{~mole} \% \mathrm{Pd}\left(\mathrm{PPh}_{3}\right)_{4}, 2 \mathrm{M} \mathrm{K}_{2} \mathrm{CO}_{3}, \mathrm{THF}, 80^{\circ} \mathrm{C}$.

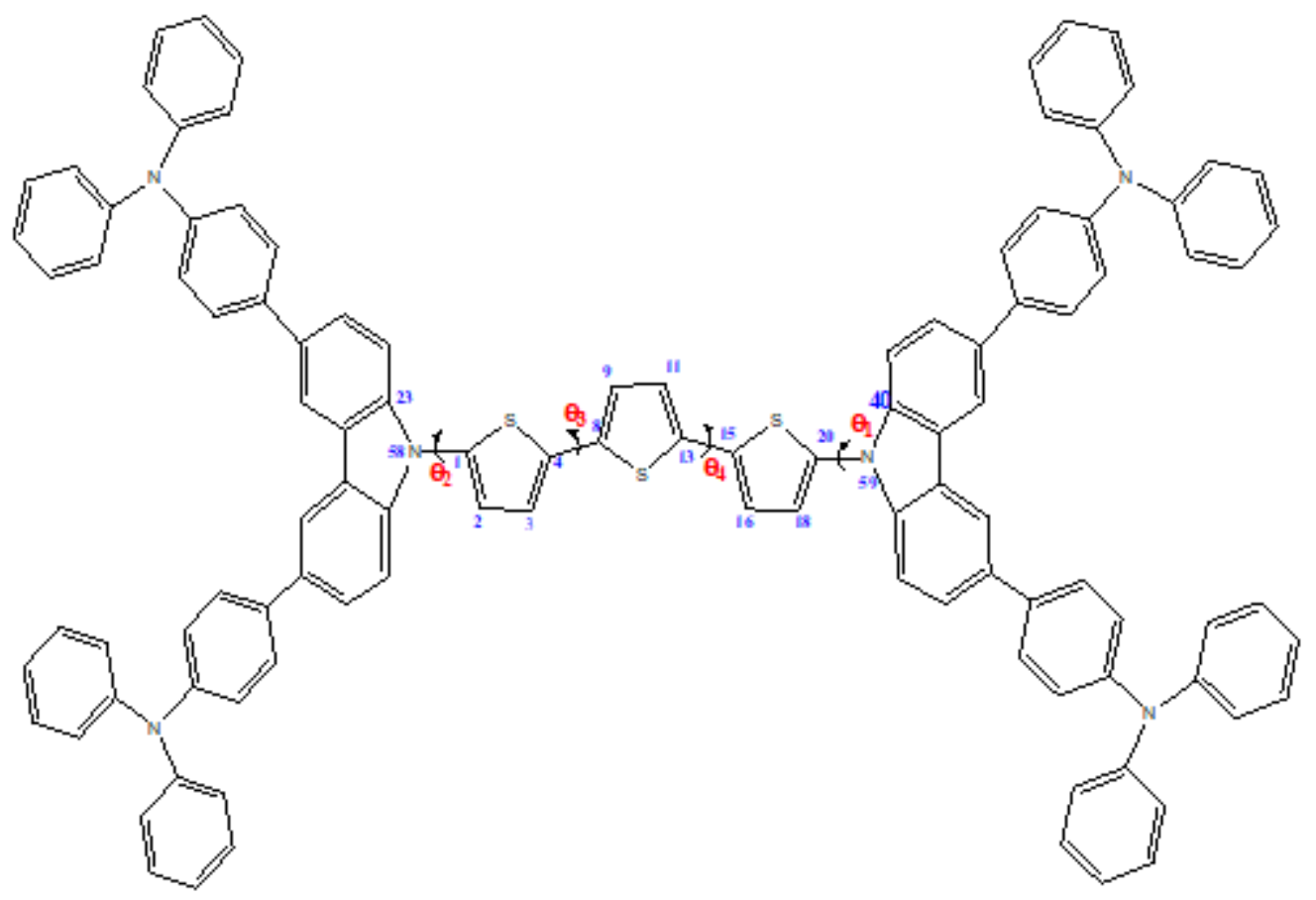

Figure 3

Numbering of distances and bond angles of the basic compound G2TTPG23T 


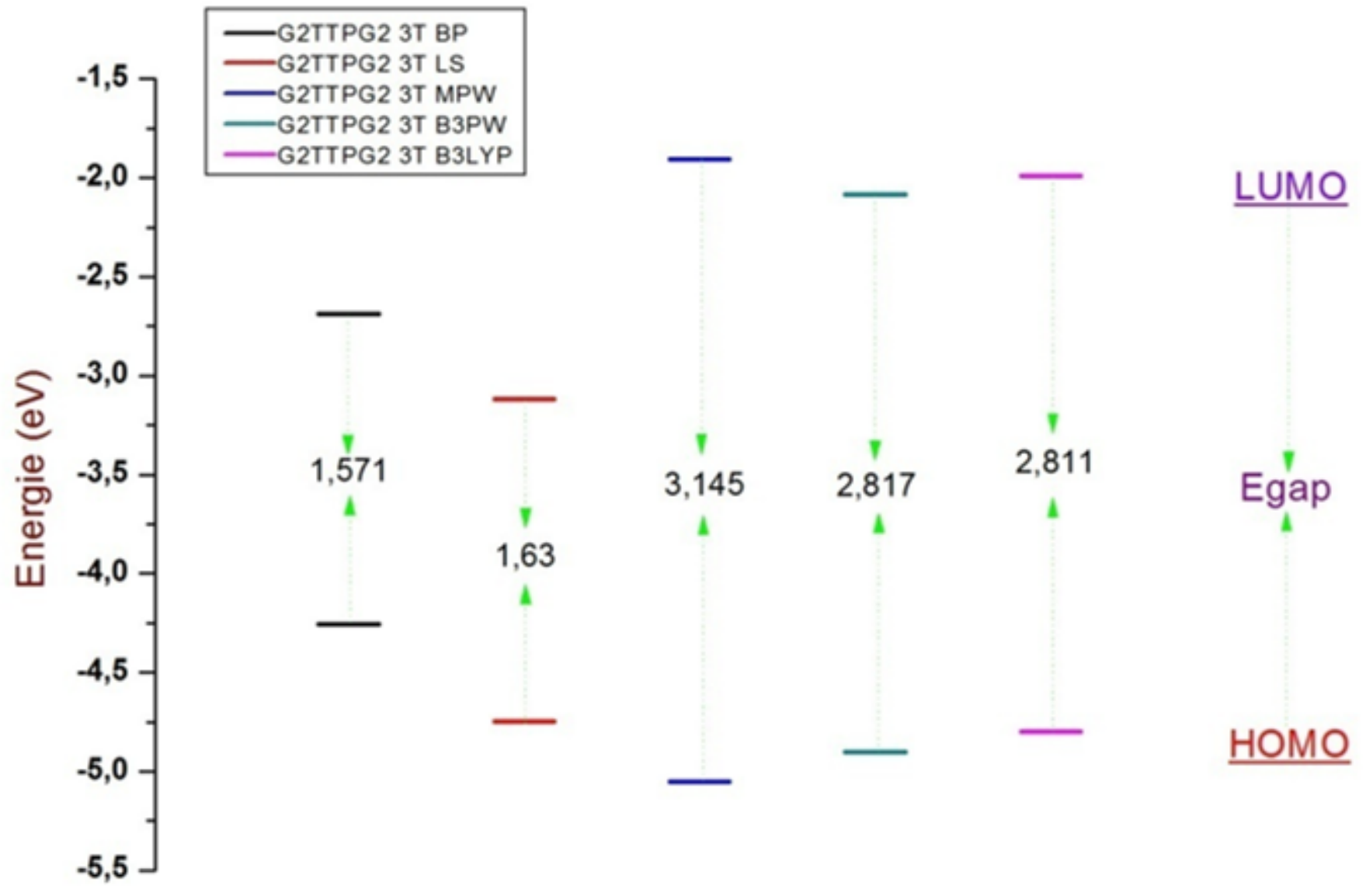

Figure 4

Energy diagram of the HOMO and LUMO levels of the basic molecule G2TTPG2 3T obtained by different calculation methods 


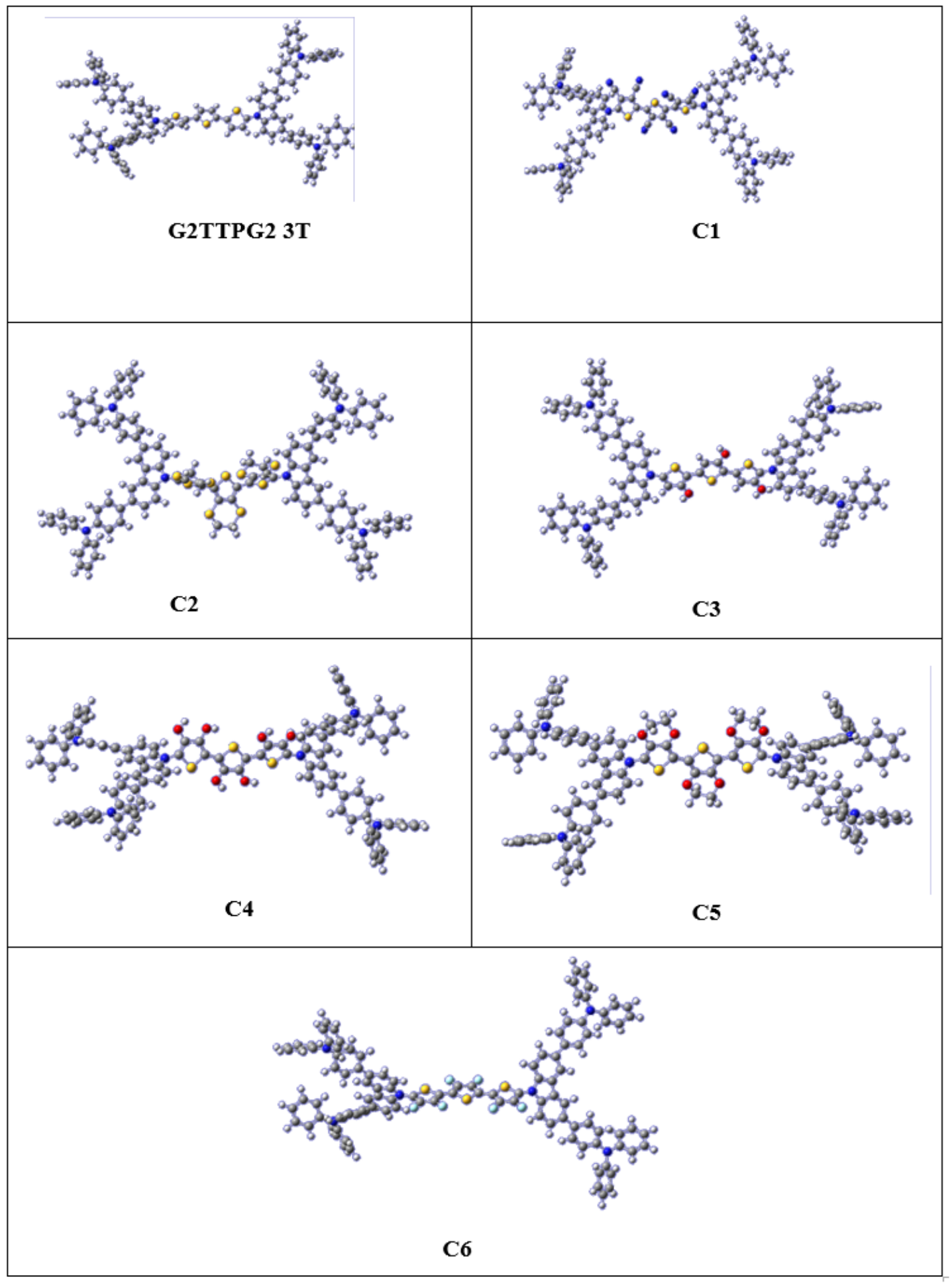

Figure 5

Optimized structures of G2TTPG2 3T and its derivatives Ci ( $i=1$ to 6$)$ obtained by DFT /B3LYP/6-31G (d, p) level 


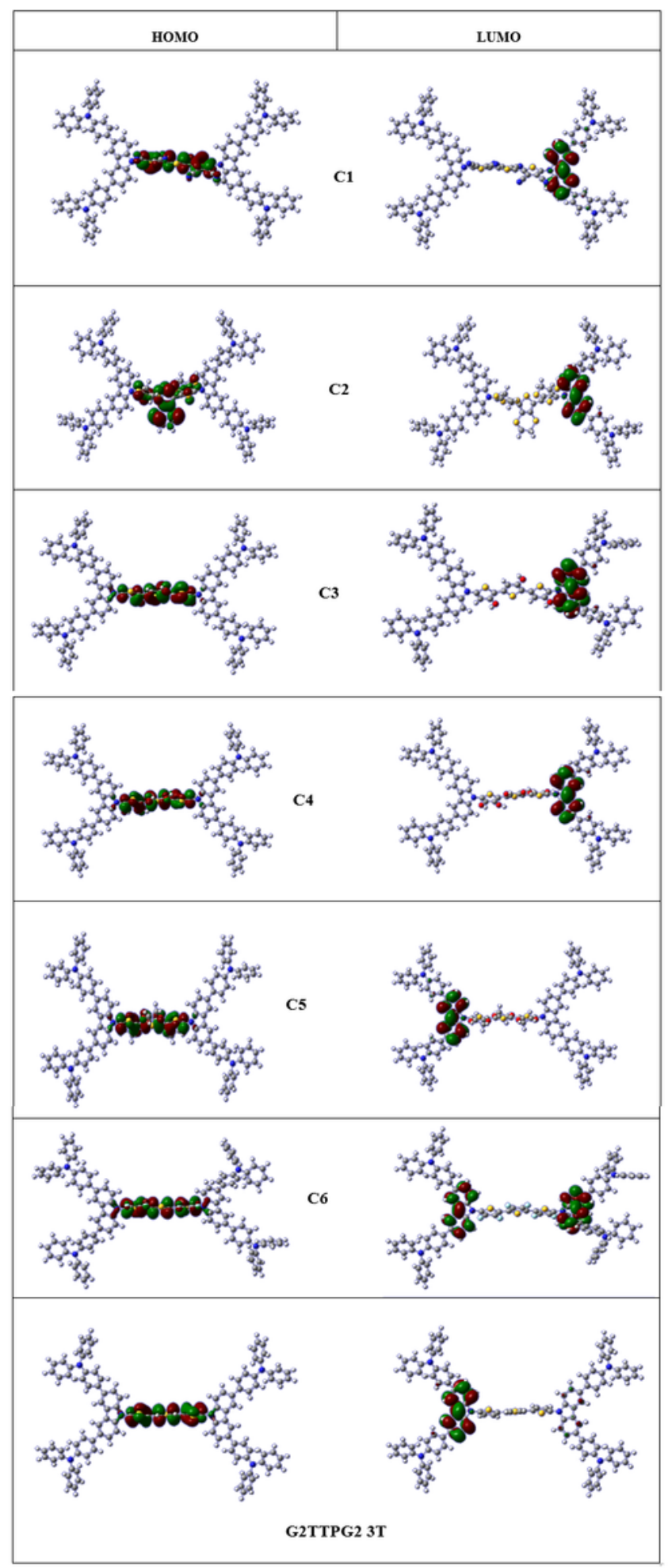

Figure 6

Obtained isodensity plots of the frontier orbital HOMO and LUMO for the studied compounds $\mathrm{Ci}$ ( $\mathrm{i}=1$ to 6 ) and the basic molecule obtained by

DFT /B3LYP/6-31G (d, p) level. 


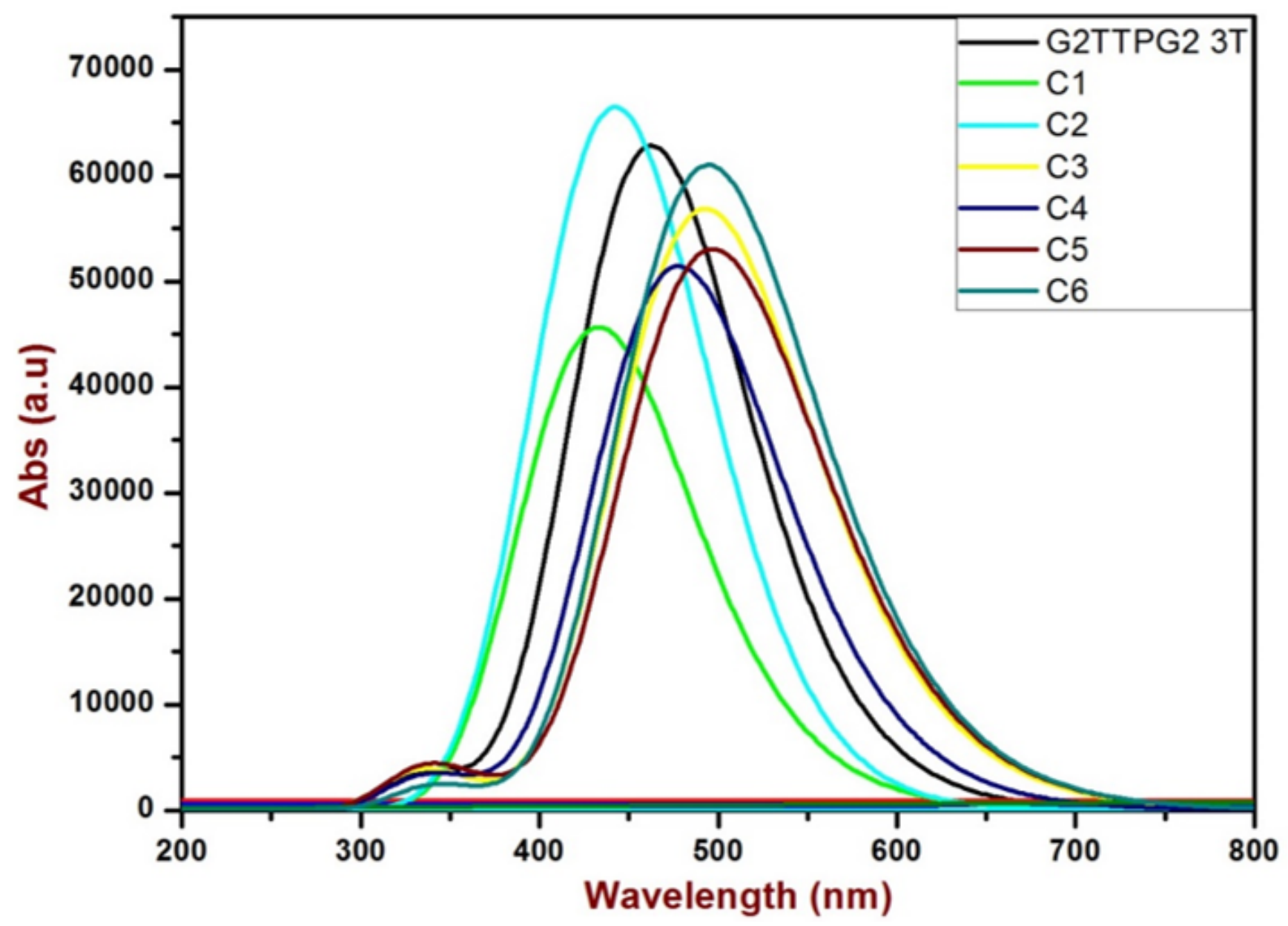

Figure 7

UV-visible optical absorption spectra of the studied compound Ci(i=1 to 6$)$ and the basic molecule obtained by the TD-DFT: B3LYP/6-31G (d.p) method 


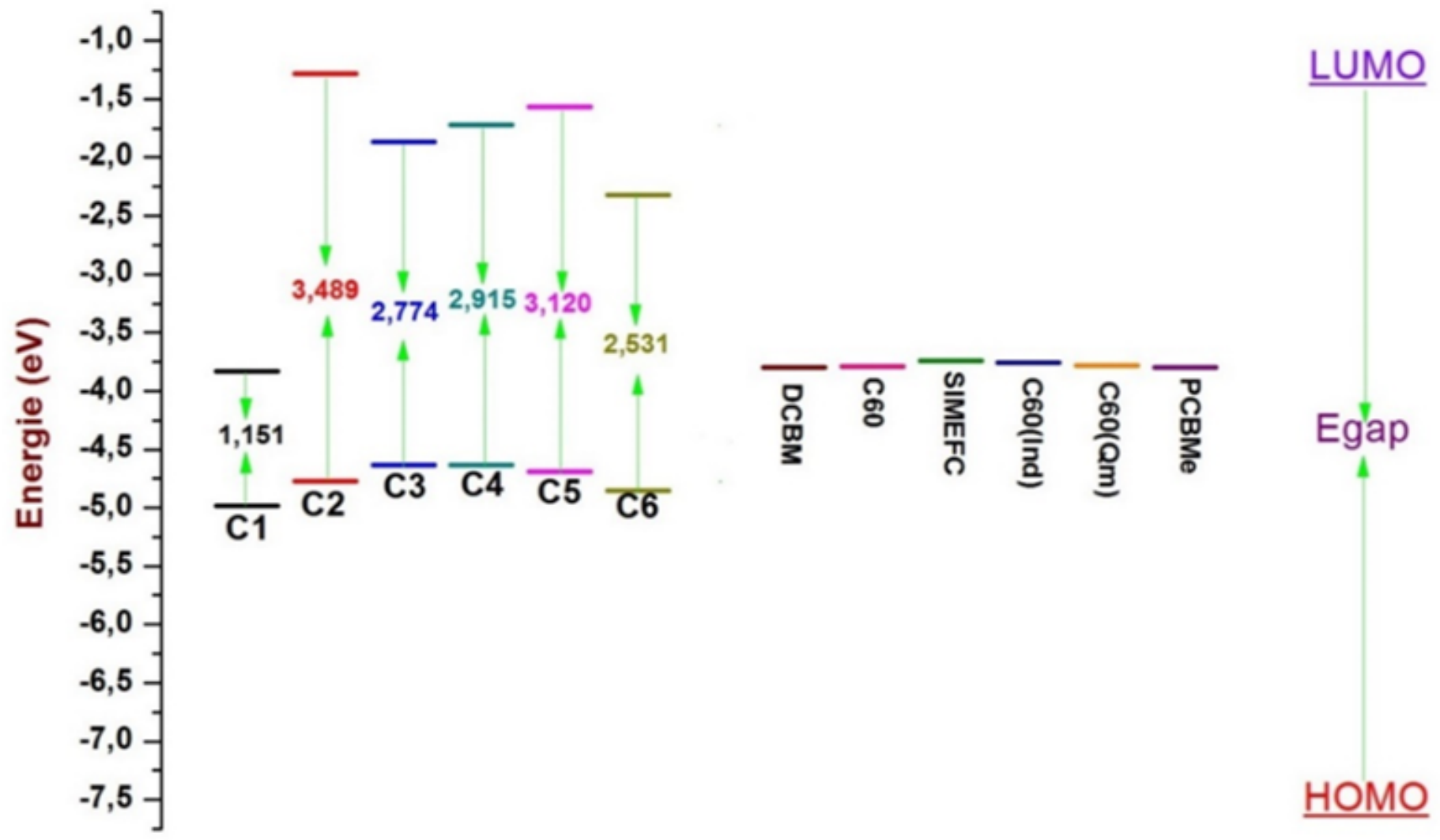

Figure 8

Energy diagram of the studied compounds $\mathrm{Ci}$ ( $\mathrm{i}=1$ to 6$)$ blended with the different acceptors PCBM. C60. SIMEFC. C60(Ind). C60(Qm) and PCBMe 